\title{
Identification of a Major Genetic Determinant of Glycaemic Index in Rice
}

\author{
M. A. Fitzgerald • S. Rahman • A. P. Resurreccion • \\ J. Concepcion • V. D. Daygon - S. S. Dipti - K. A. Kabir • \\ B. Klingner • M. K. Morell • A. R. Bird
}

Received: 3 November 2011 / Accepted: 29 November 2011 /Published online: 17 December 2011

(C) Springer Science+Business Media, LLC 2011

\begin{abstract}
Type II diabetes is a major chronic disease. In developing countries, the prevalence of type II diabetes is increasing enormously. Much research indicates that choice of carbohydrates, particularly those with low glycaemic index (GI) is able to assist in the management or prevention of type II diabetes. Most developing countries consume rice as the staple. The objectives of this study were to determine the variability in the GI of popular improved and traditional varieties of rice and to find the genetic basis of GI. A method to predict GI using an in vitro system was compared to the in vivo system using a range of rice varieties differing in GI. Large variability in GI, ranging from low to high GI,
\end{abstract}

Electronic supplementary material The online version of this article (doi:10.1007/s12284-011-9073-z) contains supplementary material, which is available to authorized users.

M. A. Fitzgerald $(\varangle) \cdot$ A. P. Resurreccion · J. Concepcion ·

V. D. Daygon $\cdot$ S. S. Dipti

Grain Quality Nutrition and Postharvest Centre, International Rice

Research Institute,

DAPO 7777 Metro Manila, Philippines

e-mail: m.fitzgerald@irri.org

S. Rahman $\cdot$ M. K. Morell

CSIRO Division of Plant Industry,

GPO Box 1600, Canberra ACT 2601, Australia

S. Rahman $\cdot$ B. Klingner $\cdot$ M. K. Morell $\cdot$ A. R. Bird

CSIRO Food Futures National Research Flagship,

PO Box 93, North Ryde NSW 1670, Australia

S. S. Dipti · K. A. Kabir

Grain Quality and Nutrition Division, Bangladesh Rice Research Institute (BRRI),

Gazipur 1701, Bangladesh

B. Klingner $\cdot$ A. R. Bird

CSIRO Food and Nutritional Sciences,

PO Box 10041, Adelaide BC, SA, Australia was found using a set of 235 varieties. The major gene that associated with GI in the 235 varieties was the Waxy gene. This paper reports the first large-scale phenotyping of this trait, provides important information for nutritionists to identify and quantify the impact of low GI rices on blood sugar status and offers a mechanism for breeding programmes to select for GI based on amylose content. Furthermore, it allows rice consumers to select particular varieties of rice as their choice of carbohydrate.

Keywords Glycaemic index · Rice · Type II diabetes · Amylose

\section{Introduction}

Type II diabetes is a major global health problem and its prevalence is increasing dramatically throughout the world, especially in Asia (Chan et al. 2009; Danaei et al. 2011). By 2030, almost 330 million people will be affected by diabetes and the greatest burden of this disease will be borne primarily by the socioeconomically disadvantaged in low and middle income societies (Misra et al. 2010; Walgate 2008). In those communities, the populace has limited access to basic health services and the presence of diabetes is often only discovered when serious complications arise, such as cardiac and kidney failure and peripheral vascular damage leading to strokes, blindness and amputations of toes, feet and limbs (Walgate 2008).

The escalating diabetes pandemic is largely a consequence of the shift away from traditional lifestyles and dietary patterns to increasingly sedentary behaviours coupled with excess intake of energy dense foods and rising rates of obesity. A growing body of evidence from epidemiological and clinical studies points to the adverse health 
consequences of foods and diets rich in carbohydrates which are readily and extensively digested (Brand-Miller et al. 2009; Hu et al. 2001; Sluijs et al. 2010). Mechanistic studies demonstrate that chronically elevated blood glucose levels induce deleterious structural changes in many tissues of the body, in particular the macro- and microvasculature (Kaushik et al. 2009). Postprandial glycaemia is emerging as a clinically useful independent risk factor for cardiovascular disease in non-diabetics and those with established diabetes (Sheu et al. 2011). Carbohydrate-based foods which elicit a modest metabolic response, namely slowed or delayed postprandial intestinal glucose absorption and consequent insulin secretion are likely to be of benefit for reducing risk of chronic diseases, such as type II diabetes. There is also a growing body of data suggesting that certain populations are inherently more susceptible to developing type II diabetes (Kooner et al. 2011); for such people, dietary options for managing blood glucose levels are important.

The glycaemic index (GI) ranks foods (and diets) on the basis of their propensity to raise blood glucose, thereby providing a relative measure of dietary carbohydrate quality. A prospective cohort study showed that dietary GI and glycaemic load $(\mathrm{GL}=0.01 \mathrm{GI} \times$ grams of carbohydrate consumed) were positively associated with diabetes risk (Barclay et al. 2008; Halton et al. 2008). Subsequent research has confirmed those findings and generated strong evidence from meta-analysis and meta-regression studies demonstrating that low GI diets are linked to improved risk markers for prevention of type II diabetes and its comorbidities (Barclay et al. 2008; Brand-Miller et al. 2003; Halton et al. 2008; Livesey et al. 2008; Marsh and BrandMiller 2008; Opperman et al. 2004; Wolever and Mehling 2002). Lower GI foods and diets provoke only transient, moderate postprandial glycaemia and improve insulin sensitivity along with other endpoints of cardio-metabolic health in obese and overweight subjects as well as those with type II diabetes (Brand-Miller et al. 2003; Dickinson and Brand-Miller 2005; Livesey et al. 2008; Marsh and Brand-Miller 2008; Opperman et al. 2004; Wolever and Mehling 2002). Furthermore, low GI diets improve metabolic health indices independent of the amount of carbohydrate consumed (Psaltopoulou et al. 2010). Accordingly, lowering the GI of the diet could help in preventing the development and slowing the progression of type II diabetes and thereby lead to an improvement in public health. It also may offer a practical means for diabetes sufferers in low income countries to better manage their condition without expensive medication.

For the majority of the world's population, polished rice is a dietary staple and has been since its domestication many thousands of years ago (Sweeney and McCouch 2007). It serves as the primary source of dietary energy and carbohydrates for most Asians, and increasingly for Africans, especially those in poorer urban and rural communities (www.irri.org). However, prospective cohort studies in genetically divergent populations show that white rice consumption is associated with increased risk of developing type II diabetes independent of ethnicity (Murakami et al. 2006; Sun et al. 2010). In a study of middle-aged Chinese women, type II diabetes risk was $78 \%$ greater in those consuming more than $300 \mathrm{~g}$ rice/day relative to those eating $<200 \mathrm{~g} /$ day (Villegas et al. 2007). Whereas white rice has been shown to adversely affect metabolic health, brown rice may be protective. In a study of US men and women, a moderate inverse association between diabetes risk and brown rice consumption was observed (Sun et al. 2010); however, varietal differences were not taken into account. Furthermore, brown rice intakes were overall very low and the results may have been confounded, in that certain populations of rice eaters often have healthier diets and lifestyles (Batres-Marquez and Jesen 2009; Fulgoni et al. 2010). Further, two studies that tested the GI of brown and white rice of the same variety, each using different varieties, reached opposing conclusions (Brand-Miller et al. 1992; Panlasigui and Thompson 2006).

Replacing white with brown rice or other whole grains has been recommended to mitigate the adverse metabolic consequences associated with refined rice consumption (Dixit et al. 2011; Kumar et al. 2011; Sun et al. 2010). However, consumption of brown rice is very low relative to white rice. Most Asians, for instance, consider it inferior to white rice because of its shorter shelf-life, longer cooking time and unappealing taste and texture (Zhang et al. 2010). Accordingly, strategies to encourage brown rice consumption over that of polished rice so as to improve consumer health are unlikely to be successful at the population level, whereas a more effective approach may be to reduce the glycaemic impact of polished rice through the development and introduction of suitable low GI rice varieties. Furthermore, most commonly consumed rices have a high GI irrespective of whether they are unpolished or refined (Brand-Miller et al. 2003; Lin et al. 2010).

While primary prevention of type II diabetes through more judicious food choices may be the frontline strategy, behavioural change that is sustained and of meaningful magnitude is difficult to achieve in practice, especially in the short term. Lowering the GI of staple foods such as rice is likely to be more effective in promoting public health, especially in communities in which rice accounts for a large share of dietary glycaemic load and where there are entrenched cultural preferences for consumption of white rice. Some Australian, Indonesian, Indian and Bangladeshi varieties have been reported to have lower GI than other rices, but the genetic basis of GI has not been determined. In barley, a mutation in starch synthase IIa (SSIIa) led to a significant lowering of GI (King et al. 2008). Four 
haplotypes of SSIIa are known in rice, two of which are inactive (Cuevas et al. 2010b; Waters et al. 2006), and if the enzymes operate the same way in barley and rice, this could lead to greater understanding of differences in GI in rice. Understanding this could enable breeding programmes to target this trait, leading to new varieties with even lower GI values than are currently known for rice.

The purpose of the present study was to establish the major genetic determinants of GI in rice for informing future varietal development. The GIs of a diverse set of Asian rices, both improved and traditional varieties, were predicted using a newly developed, high throughput instrument designed to simulate carbohydrate assimilation in the human gut. The relationship between the predictive method and in vivo measurements of GI was confirmed on a subset of lines. A secondary objective of the study was to offer an insight as to whether rice improvement programmes have changed the glycaemic properties of rices commonly eaten in Asian countries.

\section{Results}

\section{Method validation}

In vivo values of GI were determined for both the International Rice Research Institute (IRRI) and Australian sets of rice at the International Diabetes Institute and the University of Sydney, respectively. The available carbohydrate for both sets was calculated by the direct method, and GI was predicted for both sets. Figure 1 shows that the in vivo values of GI associate well with the in vitro values (Fig. 1).

Association between GI and grain properties

Using a diverse set of rices from different countries and germplasm classes, the predicted GI values range from 48 to 92 (Fig. 2), spanning low, intermediate and high GI categories, with an average reading of 64 . Predicted GI also associates with amylose content (Fig. 3a) for the 235 varieties, with increasing amylose content leading to decreased values of GI. In Fig. 3a, clusters can be seen for high, intermediate, low and waxy rices. Table 1 shows that for most alleles of the $W x$ gene, the average GI values are significantly different, with the $w x$ allele showing the highest GI and the $W x^{a}$ allele showing the lowest values of GI. Figure $3 \mathrm{~b}$ shows that one waxy, IRIS 6-59997, one low, IRIS 298-52752 and four high amylose, IRIS 266-4060, IRIS 249-1353606, IRIS 249-1353606 and IRIS 109-8916 (Table S1) varieties lie beyond the lower boundary of the interquartile range, and four high amylose varieties lie above the upper boundary. The activity of SSlla in each

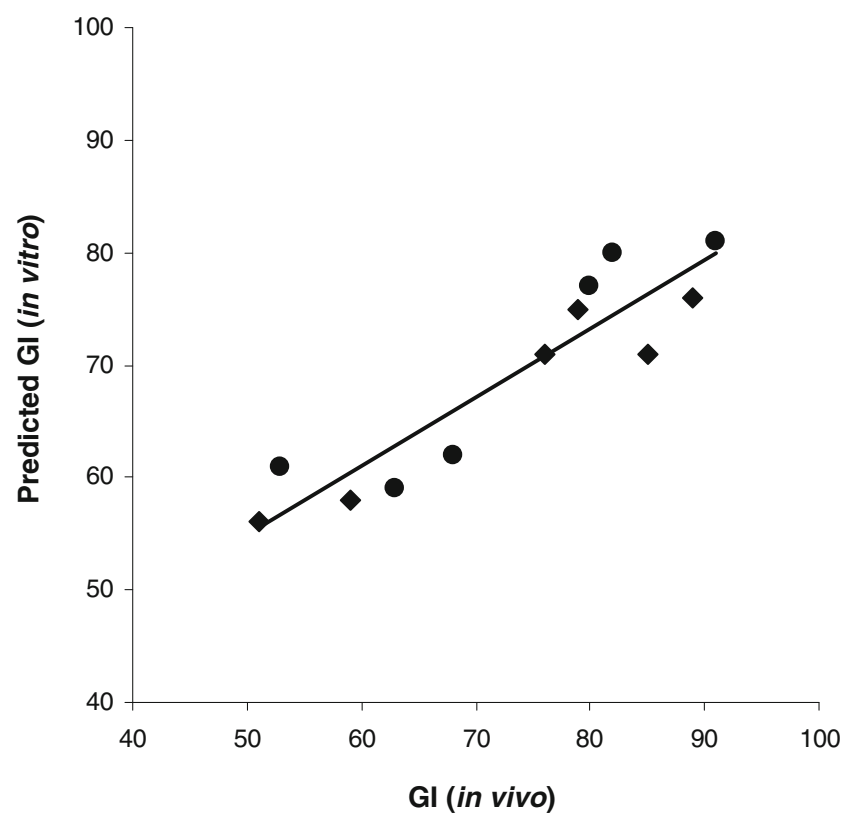

Fig. 1 Correlation $\left(r^{2}=0.85\right)$ between in vitro and in vivo measures of GI in 12 varieties of rice. Diamonds are in vivo values from the literature (Williams et al. 2005) with in vitro values tested in this study, and circles represent varieties for which in vitro and in vivo values are from the present study.

sample was determined by genotyping for the four haplotypes (Cuevas et al. 2010a). No significant difference was found between SSlla haplotype and GI, nor was there any interaction or modifying effect of SSlla haplotype on the association between amylose alleles and GI (data not shown).

High amylose rices, those carrying the $W x^{a}$ allele, differ in the texture of the cooked rice in that some are soft and some are firm. Using progeny from a mapping population derived from parents both with the $W x^{\mathrm{a}}$ allele and segregating for cooked rice texture, the predicted GI was $60 \pm 6$ for the soft textured progeny and $59 \pm 4$ for the firm-textured progeny.

Figure 4 shows that traditional varieties, selected by ancient farmers, are not of significantly different GI than improved varieties, with the average GI of improved varieties being 64.9 and of traditional, 64.0. However, traditional varieties do not show so many high GI samples as improved varieties, so the weighted average GI of these is 63 , whereas it is 68 for the improved varieties.

\section{Discussion}

The prevalence of lifestyle-related chronic diseases and conditions, such as obesity, cardiovascular disease, certain cancers and type II diabetes is continuing to grow at an alarming pace throughout the world, the Asian region 
Fig. 2 Range in predicted GI values of 235 varieties of cooked, polished rice.

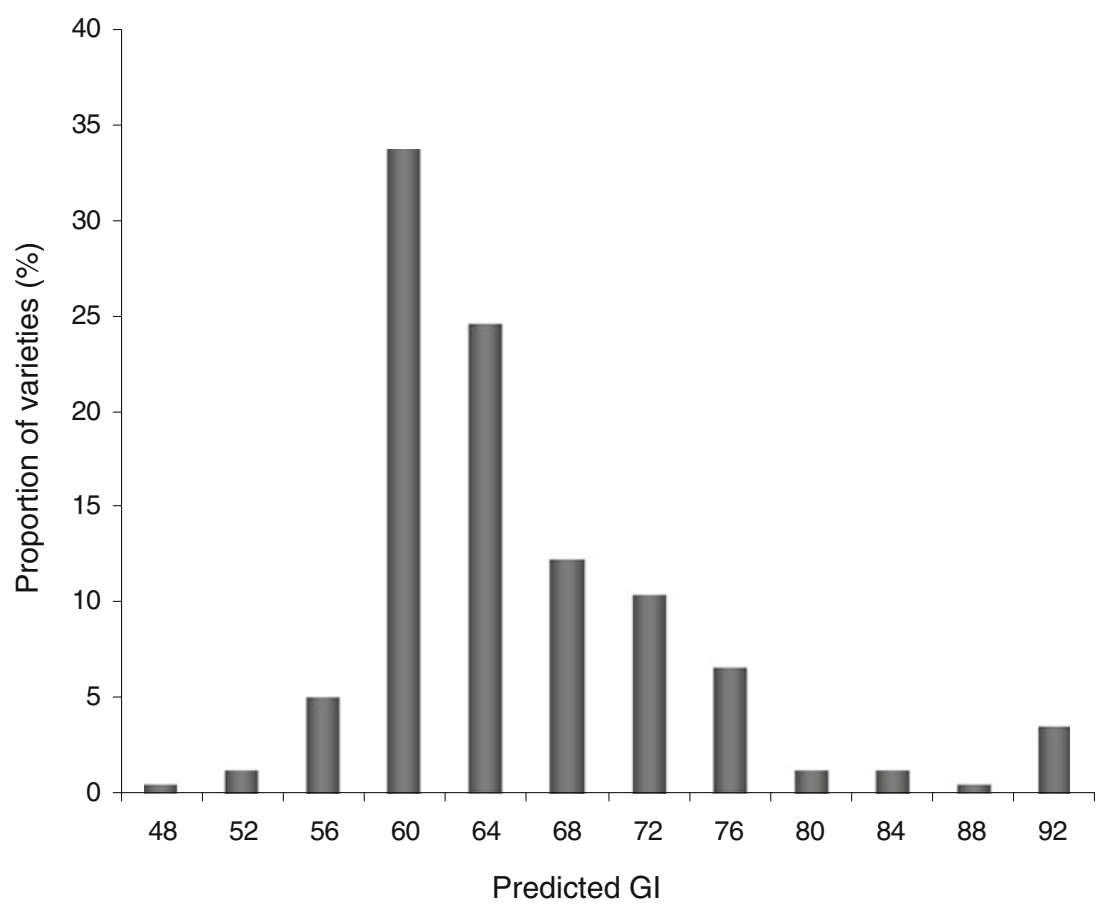

especially (Shaw et al. 2010). Diet is implicated in the onset and progression of these health problems and carbohydrate quality is a strong predictor of disease risk. Choosing to eat foods with predominately slowly digestible carbohydrates has been shown to be linked to favourable health outcomes including reduced risk of type II diabetes and related conditions (Barclay et al. 2008; Halton et al. 2008; Livesey et al. 2008; Marsh and Brand-Miller 2008).

Rice is a traditional staple food and primary dietary source of carbohydrates for most Asians and is increasingly

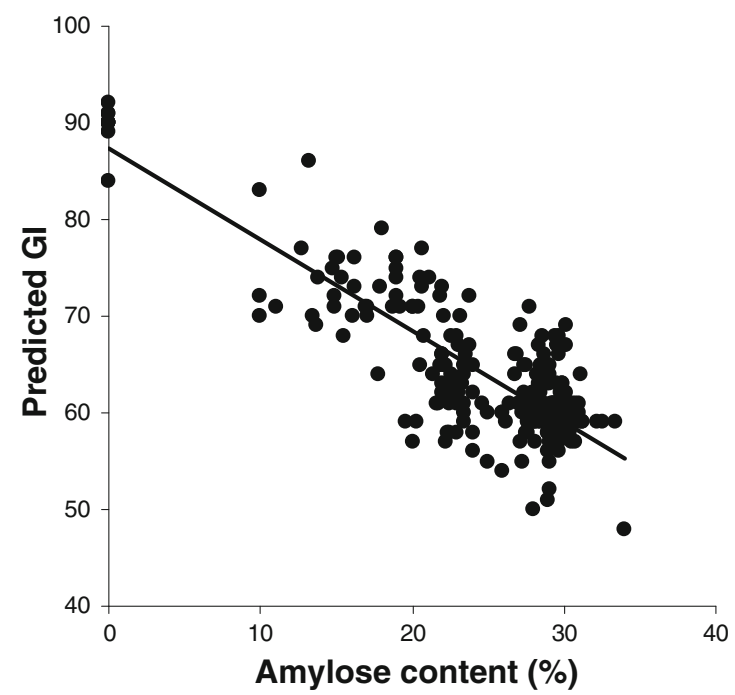

Fig. 3 a Correlation $\left(r^{2}=0.73\right)$ between amylose content and predicted GI using 235 diverse samples and $\mathbf{b}$ box and whiskers plot of GI vs. amylose content showing that most samples associate with amylose playing the same role in African diets. Improving the carbohydrate quality of this popular commodity offers potential as a dietary strategy for preventing and managing type II diabetes and its co-morbidities, thereby promoting population health and alleviating the public health burden of chronic diseases. In countries with very high incidences of type II diabetes, such as Sri Lanka, Bangladesh, Indonesia, Malaysia and India, there is a belief that specific varieties of rice can elicit lower glycaemic responses and these are sold and marketed to type II patients.

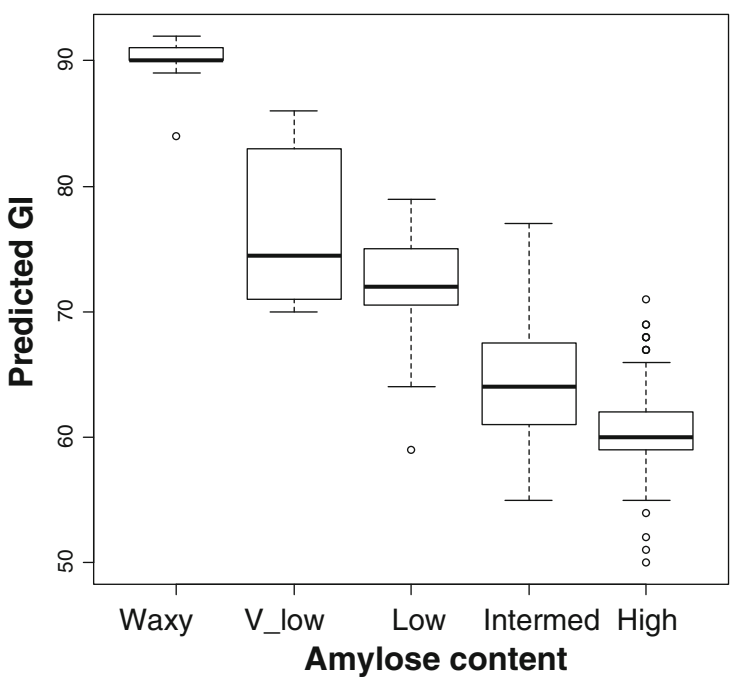

content, but for those with high amylose, a number of outliers extend in both directions beyond the interquartile range. 
Table 1 Average GI is significantly different between each known allele of the Waxy gene using the Welch's $T$ test and pairwise comparisons $(p<0.05)$. Different letters indicate signficant differences in GI values

GI glycaemic index

GI provides a measure of the glycaemic potency of foods and is widely used as a guide for choosing healthier foods (Chiu et al. 2011; Mitchell 2008). Low GI diets are effective in the prevention and treatment of type II diabetes (Barclay et al. 2008; Gnagnarella et al. 2008; Jenkins et al. 2002). However, rice improvement programmes have not been able to focus on the development of varieties with potential for reducing the incidence and severity of type II diabetes because variability for GI in rice is unknown, the genetics of GI are unknown and phenotyping tools for nutritional traits, such as GI, are not yet available.

Although a number of studies have attempted to draw associations between components of the grain and the GI of the rice (Babu et al. 2007; Brand-Miller et al. 1992; Frei et al. 2003; Hettiarachchi et al. 2001; Hu et al. 2004; Matsuo et al. 1999; Panlasigui et al. 1991), establishing relationships between composition and genotypes of rices and GI has been hampered by the low throughput, poor precision and considerable expense of in vivo determination of GI (De
Vries 2007; Muller and Bird submitted). Consequently, previous studies have measured GI on only a small subset of rice varieties and so variability in the diversity of rice is not captured and definitive conclusions about possible relationships between GI and other grain traits cannot be drawn.

GI is a numerical measure of the extent to which carbohydrates in foods affect postprandial blood glucose levels. Conventional GI determination therefore involves testing in humans. For most applications, this is impractical for the reasons stated earlier. Indeed, stringent testing conditions are essential to achieve satisfactory levels of precision (De Vries 2007; Muller and Bird submitted; Pi-Sunyer 2002; Venn and Green 2007). In the present study, we demonstrate that the use of an automated laboratory-based assay for predicting GI overcomes the methodological and ethical constraints of in vivo testing and provides a practical solution to screening large volumes of samples. The validity of the assay was established by testing a diverse set of rice varieties and comparing the results against those obtained using standardised in vivo procedures performed by two highly experienced testing agencies. Correlation analysis of the resultant data demonstrated a strong relationship between predicted and actual GI values confirming that the in vitro method has high predictive power, thereby justifying its use in the current study to explore, for the first time, the range in GI values across a large and diverse collection of improved and traditional rice varieties. The information we have generated on the relative glycaemic properties of
Fig. 4 Frequency histogram showing that the distribution in GI of improved varieties of rice (black bars) contains more high GI rices than the distribution of the traditional varieties (grey bars).

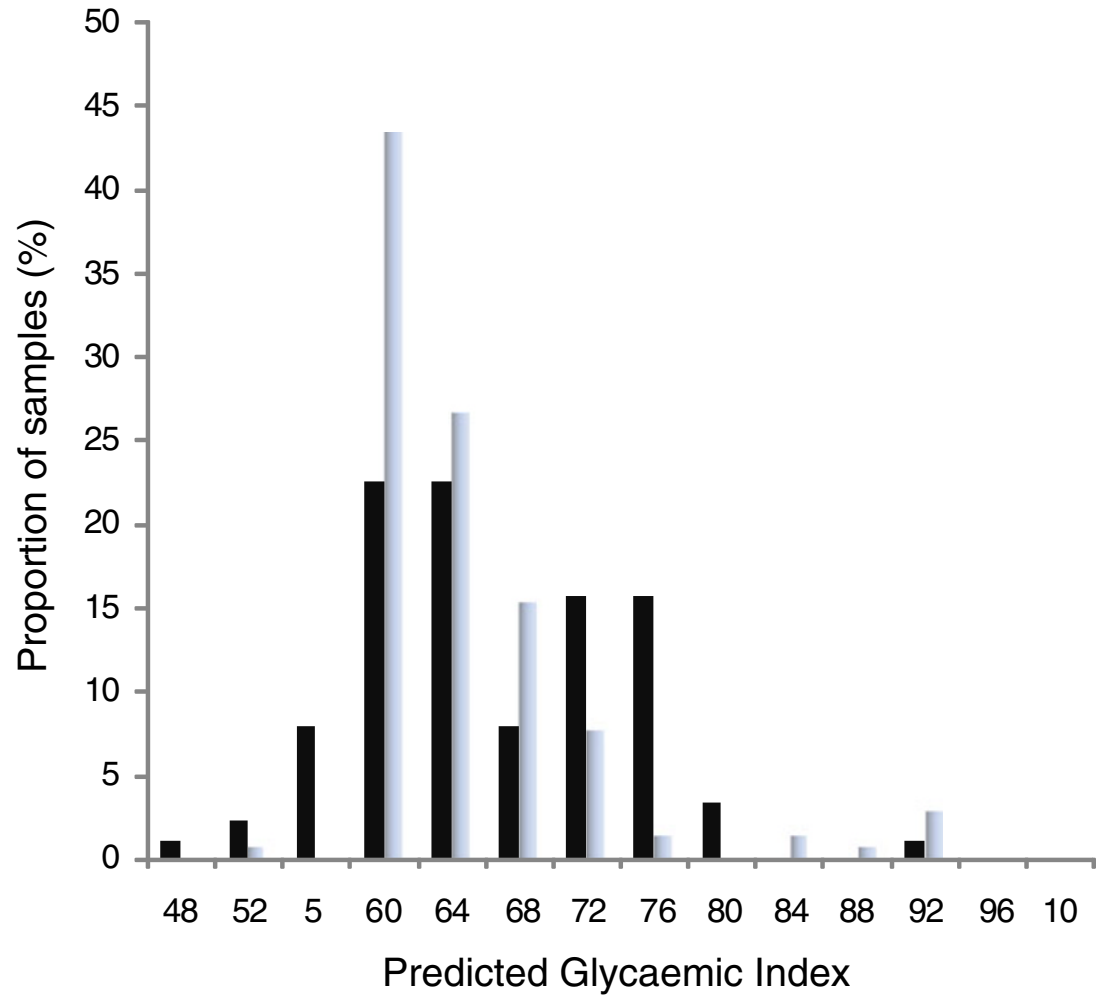


different types of rice has a wide scope of applicability. In vivo GI values for a given food are essentially the same regardless of ethnicity or physiological status of the volunteers on which the data are based (Chiu et al. 2011). Furthermore, the relationship between GI and adverse health impacts is just as pertinent to Asians as it is to Caucasians and other racial and ethnic groups (Murakami et al. 2006; Villegas et al. 2007).

The varieties measured included both landraces (143) and improved (92) varieties developed by leading rice breeding programmes in many different countries. The collection included indica and tropical and temperate japonica rices. GI ranged from 48-98 in the set of rices, with no association between germplasm class. A similar range in the GI of rices, including low GI varieties as determined by acceptable in vivo methods, has been reported previously (Brand-Miller et al. 1992; Larsen et al. 1996). While there are in vitro GI data on different rice lines (Frei et al. 2003), caution should be exercised in interpreting these findings because their physiological relevance has not been satisfactorily substantiated. Our data demonstrate that improved varieties have on average a slightly higher GI than traditional ones (Fig. 4), suggesting that breeding programmes have produced a slow, passive drift towards higher GI rices. Until recently, the nutritional potential of rice has not been a target of rice improvement programmes, and while various countries would like to develop low GI rices, the limitation lies in selecting for the trait.

Strong correlations between amylose content, the Waxy locus and GI were observed across all samples (Fig. 3a, Table 1), indicating that amylose is the major grain constituent that affects GI. However, the size of the interquartile ranges and the presence of outliers in Fig. 3b suggest that (a) within each class of amylose content, and for each allele of the Waxy gene, variability can be found for GI and (b) there must be other loci that interact with the Waxy gene to produce variability within each class. The absence of starch synthase IIa (SSlla) activity lowers GI in barley (King et al. 2008) but no association was found between varieties with active and inactive haplotypes of SSlla in this study. This suggests that SSlla plays different roles in starch synthesis in barley and rice.

In the high amylose classification of rice, the texture of freshly cooked rice can be either soft or firm (Cagampang et al. 1973). This difference is due to a single-nucleotide polymorphism in the Waxy gene that leads to different structures of amylose within the grain and different retrogradation rates (Tran et al. 2011). Intuitively, it might be assumed that amylose structure would affect the GI and that the firm-textured varieties might have a lower GI. However, the difference in GI between progeny of a mapping population with soft and firm texture after cooking was not significantly different, suggesting that the amount of amylose is more important than the structure of the amylose in determining GI.

Intermediate amylose rices are preferred in many countries in which over $5 \%$ of the population have type II diabetes. There is also a strong positive association between amylose content and texture of the rice (Bhattacharya 2009; Juliano 1979). The high amylose class contains both softand firm-textured rice, and given that there is no effect of the single-nucleotide polymorphism (SNP) on exon 10 of the $W x$ gene on GI within the high amylose class, it should be possible for breeding programmes concerned with the GI of rice to develop soft-textured high amylose rices to replace the intermediate amylose rices, especially for countries and regions with high incidences of type II diabetes, such as the Philippines, South Asia and the Middle East.

While this study has identified a major determinant of GI in rice, the data do not preclude the possibility that other genes have a modifying effect on GI. Additional studies in genetic populations will be required to identify such genes and quantify their contribution to determining GI.

The identification of low GI rice varieties offers the possibility of conducting well-designed, randomised controlled trials and epidemiological studies (long-term prospective investigations that take into account the various confounding factors operating across different populations, regional locations, culinary customs and ethnic groups) to examine the relationship between sustained consumption of low GI rice, metabolic control and health outcomes. Such information will be useful for informing the development of long-term public health strategies and clinical management plans for people with metabolic diseases.

\section{Materials and methods}

\section{Method validation}

In order to predict the GI of a large and diverse set of rice varieties with an in vitro method, it is necessary to determine the association between the in vivo method of measuring GI and the in vitro method. A set of six varieties of rice, Oryza sativa L., that have been widely researched in previous studies were selected to validate the method. These were IR65, IR24, IR64, IR8, BD192 (from Bangladesh) and Samba Mahsuri (from India). All varieties, other than BD192, were grown in the dry season of 2008 at the International Rice Research Institute in the Philippines. Grain was harvested at maturity, stored for 6 weeks to equilibrate for moisture content, then $150 \mathrm{~g}$ was dehulled (THU35A Test Husker, Satake) and polished (Grainman 60230-60-2AT, Grain Machinery Mfg. Corp.). BD192 was obtained from the Genetic Resources Centre of the Bangladesh Rice Research Institute (BRRI) and grown in 
both the Aman and Boro seasons at BRRI. Grain was harvested at maturity, dehulled (THU35A Test Husker, Satake) and polished using a home-made polisher.

Polished grain from each variety was cooked in excess water. Once the water reached a light boil, the rice was added, and after $17 \mathrm{~min}$, the rice was drained and allowed to cool for $5 \mathrm{~min}$. Total starch of the cooked rice was determined as described using the Megazyme total starch kit (Megazyme, Wicklow, Ireland) (AACC Standard 76 13.01).

In vivo testing for GI

GI of the six rices was tested according to the Australian Standard AS 4694-2007: Glycaemic Index of Foods. The tests were performed by the International Diabetes Institute testing facility, Caulfield, Victoria, Australia. Blood glucose was determined in 10 to 12 volunteers who had fasted for $10 \mathrm{~h}$ prior to the test. The volunteers then consumed the test (glucose drink) or reference food (rice) over $12 \mathrm{~min}$, and then, changes in circulating levels of blood glucose were measured over the following $2 \mathrm{~h}$. The test rices contained $50 \mathrm{~g}$ of glycaemic (available) carbohydrate, based on total starch of the cooked rice, and the reference food (glucose drink) had been tested in each volunteer on three previous occasions. The incremental area under the blood glucose curve (IAUC) was calculated and indexed to that of the mean IAUC for the reference food and then GI of each of the six rices was calculated according to the trapezoid rule. The area beneath the fasting concentration is ignored in the calculation of GI. Glucose is used as the reference food and by definition has a GI of 100 .

A second set of values of in vivo GI was previously obtained for another six Australian varieties of rice (Williams et al. 2005). These were Amaroo, Doongara, Opus, Langi, Kyeema and Basmati. Samples of each were supplied by Sunrice Cooperative Ltd to the University of Sydney and to IRRI as polished rice. Each sample was analysed for proximate analysis and amylose content to determine available carbohydrate, and GI values were obtained by the University of Sydney (Williams et al. 2005).

In vitro testing for GI

Both sets of samples that were tested for in vivo GI at the International Diabetes Institute and the University of Sydney were sent to Commonwealth Scientific and Industrial Research Organisation (CSIRO) Food Nutrition for determining predicted GI. Samples of the test rices IR65, IR24, IR64, IR8, BD192 and Samba Mahsuri were cooked using a scaled-down version of the rapid boil procedure that was used in the in vivo GI studies described previously.
Quantities of raw test rices equating to $5 \mathrm{~g}$ of glycaemic (available) carbohydrate were added to an excess of boiling water (approximately $60 \mathrm{~mL}$ ) and cooked for $16 \mathrm{~min}$. The rices were then drained using a domestic sieve and allowed to cool for $5 \mathrm{~min}$ at room temperature before intact rice grains were assayed immediately for their predicted GI using an in vitro system which models the buccal, gastric and pancreatic phases of food digestion as it occurs in the human upper gastrointestinal tract (Bird, Usher, Klingner, Topping and Morrell, unpublished data). Briefly, cooked rices were added to a conical flask and mixed with artificial saliva $(250 \mathrm{U} / \mathrm{mL}$ of $\alpha$-amylase $)$ at $\mathrm{pH}$ 7.0. After approximately $20 \mathrm{~s}$, acidified $(0.02 \mathrm{M} \mathrm{HCl})$ pepsin $(1 \mathrm{mg} / \mathrm{mL})$ was added and the flask incubated at $37^{\circ} \mathrm{C}$ for $30 \mathrm{~min}$ in a shaking water bath. The digest was adjusted to $\mathrm{pH} 6.0(0.2 \mathrm{M}$ acetate buffer $\mathrm{pH} 6.0)$ followed by the addition of pancreatin $(2 \mathrm{mg} / \mathrm{mL})$ and amyloglucosidase $(28 \mathrm{U} / \mathrm{mL})$ and the digest incubated for a further $5 \mathrm{~h}$. Aliquots of supernatant were sampled at preset intervals and the glucose concentration determined using an automated electrochemical technique (YSI 2700 Select Bioanalyser) (Yellow Springs, OH). The predicted GIs of the rices were calculated as a percentage of available $\mathrm{CHO}$ converted to glucose over the duration of the incubation.

Range in predicted GI using diverse varieties of rice

A set of 111 varieties was randomly selected from the Genetic Resources Centre of (BRRI). Of these, 72 were traditional varieties and 39 were improved. A second set was selected at IRRI to represent the popular and traditional varieties of many other Asian countries. All samples (235) were shipped to CSIRO as polished grain for the prediction of GI by the in vitro method described above.

Association between grain properties and GI

A set of 40 samples from a population $\left(\mathrm{F}_{7}\right)$ of recombinant inbred lines derived from a cross between two high amylose varieties, IR5 and IR8, were selected to determine whether predicted GI associates with the texture of the grain after cooking. Twenty soft-textured and 20 firm-textured progeny were selected for GI testing. Cooked rice texture of the 40 samples was measured by the gel consistency test and confirmed by texture profiling using a TaXt-plus as described previously (Tran et al. 2011). Amylose content was measured on the 235 varieties of rice, including those used to validate the method, by the standard method (AACC-6647), except that an additional standard was included in the standard curve, IR65, which is a waxy variety and contains no amylose. 
Three SNPs at the Waxy locus, on the splice site of exon 1 , exons 4 and 6 , define the haplotypes that associate with amylose class. DNA was extracted from each sample (Fitzgerald et al. 2008). The SNP status (G/T) at exon 1 was determined by amplifying a region containing the SNP using primer pair RM190, and then, a restriction enzyme, Acc1 (New England BioLabs), which splices when a G is present at the site (Ayres et al. 1997). The presence of $T$ at the site signifies low amylose. Intermediate and high amylose varieties were genotyped for SNP status at exon $6(\mathrm{~A} / \mathrm{C})$ using allele-specific primers (5'-CCC ATA CTT CAA AGG AAC ATA-3', 5' - GGT TGG AAG CAT CAC GAG TT - 3' and 5' - TCT TCA GGT AGC TCG CCA GT - 3'), where a product size of $292 \mathrm{bp}$ indicates C (intermediate amylose) and products of 200 and 292 bp identify an A (high amylose). Very low amylose varieties were determined by genotyping the SNP on exon $4(\mathrm{~A} / \mathrm{G})$ using the primer set $\left(5^{\prime}\right.$ TGC TAC AAG CGT GGA GTG GA-3' and 5'-ACC AGT ACA AGG ACG CTT GG-3') and sequencing of the product.

The polymerase chain reaction (PCR) was performed using a G-Storm Thermal Cycler (model GS1, Gene Technologies Ltd, Essex, UK). The PCR reaction mixture contained 10 ng DNA extract, $0.16 \mathrm{mM}$ deoxynucleoside triphosphates, $2 \mathrm{mM}$ magnesium chloride, $0.4 \mathrm{mM}$ each of forward and reverse primers, $1.2 \mathrm{mM}$ allele-specific primers and 0.04 units of Intron Taq DNA polymerase (Shiga, Japan). The amplification of the targeted region was conducted under the following conditions: $5 \mathrm{~min}$ at $94^{\circ} \mathrm{C}$; 35 cycles of $40 \mathrm{~s}$ at $94^{\circ} \mathrm{C} ; 40 \mathrm{~s}$ at $55^{\circ} \mathrm{C}$; and a final extension step of $72^{\circ} \mathrm{C}$ for $10 \mathrm{~min}$. The amplified products were resolved in 2\% native agarose gel, stained with SybrSafe nucleic acid stain (Invitrogen, Carlsbad, CA, USA) and visualised with a UV transilluminator (Alpha Imager).

\section{Statistics}

Box and whisker plots were generated to identify outliers in the association between Waxy allele and GI using $R$ v. 2.13.1. Outliers extending beyond the interquartile ranges were not removed before further analysis because there were so few of them. The correlation between predicted GI and each Waxy allele was carried out by pairwise comparisons using the Welch's $T$ test in $R$. Differences were significant when $p<0.05$.

\section{References}

Ayres NM, McClung AM, Larkin PD, Frances H, Bligh J, Jones CA, Park WD. Microsatellites and a single-nucleotide polymorphism differentiate apparent amylose classes in an extended pedigree of US rice germ plasm. Theor Appl Genet. 1997;94:773-81.
Babu, Uma S., and Paddy L. Wiesenfeld. 2007. Rice, global food source and rice controversy related to obesity and glycemic index. In interactions of rice components and obesity-lipid biomarkers and immune function, 11-18. Kerala: Transworld Research Network.

Barclay AW, Petocz P, McMillan-Price J, Flood VM, Prvan T, Mitchell $\mathrm{P}$, Brand-Miller JC. Glycemic index, glycemic load, and chronic disease risk - a meta-analysis of observational studies. Am J Clin Nutr. 2008;87:627-37.

Batres-Marquez SP, Jesen HH. Rice consumption in the United States: recent evidence from food consumption surveys. J of Am Diet Assoc. 2009;109:1719-27.

Bhattacharya KR. Physicochemical basis of eating quality of rice. Cereal Foods World. 2009;54:18-28.

Brand-Miller JC, Pang E, Bramall L. Rice: a high or low glycemic index food? Am J Clin Nutr. 1992;56:1034-6.

Brand-Miller J, Hayne S, Petocz P, Colagiuri S. Low-glycemic index diets in the management of diabetes: a meta-analysis of randomized controlled trials. Diabetes Care. 2003;26:2261-7.

Brand-Miller J, McMillan-Price J, Steinbeck K, Caterson I. Dietray glycemic index: health implications. J Am Coll Nutr. 2009;28:4465-95.

Cagampang GB, Perez CM, Juliano BO. A gel consistency test for eating quality in rice. J Sci Food Agric. 1973;24:1589-94.

Chan JCN, Malik V, Jia WP, Kadowaki T, Yajnik CS, Yoon KH, Hu FB. Diabetes in Asia epidemiology, risk factors, and pathophysiology. J Am Med Assoc. 2009;301:2129-40.

Chiu CJ, Liu S, Willett WC, Wolever TM, Brand-Miller JC, Barclay AW, Taylor A. Informing food choices and helath outcomes by use of the dietary glycemic index. Nutr Rev. 2011;69:231-42.

Cuevas RM, Daygon VD, Corpuz HM, Waters DLE, Reinke RF, Fitzgerald MA. Melting the secrets of gelatinisation temperature. Funct Plant Biol. 2010a;37:439-47.

Cuevas RP, Daygon VD, Corpuz HM, Reinke RF, Waters DLE, Fitzgerald MA. Melting the secrets of gelatinisation temperature in rice. Funct Plant Biol. 2010b;37:439-47.

Danaei G, Finucane MM, Yuan Lu, Singh GM, Cowan MJ, Paciorek CJ, Lin JK, Farzadfar F, Khang Young-Ho, Stevens GA, Rao M, Ali MK, Riley LM, Robinson CA, Ezzati M. National, regional, and global trends in fasting plasma glucose and diabetes prevalence since 1980: systematic analysis of health examination surveys and epidemiological studies with 370 country-years and 2.7 million participants. Lancet. 2011;378:31-40.

De Vries JW. Glycemic index: the analytical perspective. Cereal Foods World. 2007;52:45-9.

Dickinson S, Brand-Miller J. Glycemic index, postprandial glycemia and cardiovascular disease. Curr Opini in Lipidol. 2005;16:69-75.

Dixit AA, Azar KM, Gardner CD, Palaniappan LP. Incorporation of whole, ancient grains into a modern Asian Indian diet to reduce the burden of chronic disease. Nutr Rev. 2011;69:479-88.

Fitzgerald MA, Sackville-Hamilton NR, Calingacion MN, Verhoeven $\mathrm{HA}$, Butardo Jr V. Is there a second gene for fragrance in rice? Plant Biotechnol J. 2008;6:416-23.

Frei M, Siddhuraju P, Becker K. Studies on the in vitro starch digestibility and the glycemic index of six different indigenous rice cultivars from the Philippines. Food Chem. 2003;83:395-402.

Fulgoni VL, Fulgoni SA, Upton JL, Moon M. Diet quality and markers for human health in rice eaters versus non-rice eaters: an analysis of the US National Health and Nutrition Examination Survey, 1999-2004. Nutrion Today. 2010;45:262-72.

Gnagnarella P, Gandini S, La Vecchia C, Maisonneuve P. Glycemic index, glycemic load, and cancer risk: a meta-analysis. Am J Clin Nutr. 2008;87:1793-801.

Halton TL, Liu S, Manson JoAnn E, Frank BHu. Low-carbohydrate-diet score and risk of type 2 diabetes in women. Am J Clin Nutr. 2008;87:339-46. 
Hettiarachchi P, Jiffry MTM, Jansz ER, Wickramasinghe AR, Fernando DJS. Glycaemic indices of different varieties of rice grown in Sri Lanka. Ceylon Med J. 2001;46:11-4.

Hu FB, van Dam RM, Liu S. Diet and risk of Type II diabetes: the role of types of fat and carbohydrate. Diabetologia. 2001;44:805-17.

Hu PS, Zhao HJ, Duan ZY, Zhang LL, Dian-xing Wu. Starch digestibility and the estimated glycemic score of different types of rice differing in amylose contents. J of Cereal Sci. 2004;40:231-7.

Jenkins DJA, Kendall CWC, Augustin LSA, Franceschi S, Hamidi M, Marchie A, Jenkins AL, Axelsen M. Glycemic index: overview of implications in health and disease. Am J Clin Nutr. 2002;76:266S73.

Juliano BO. The chemical basis of rice grain quality. Workshop on Chemical Aspects of Rice Grain Quality. Los Banos: International Rice Research Institute; 1979.

Kaushik S, Wang JJ, Wong TY, Flood V, Barclay A, Brand-Miller J, Mitchell P. Glycemic index, retinal vascular caliber, and stroke mortality. Stroke. 2009;40:206-12.

King RA, Noakes M, Bird AR, Morell MK, Topping DL. An extruded breakfast cereal made from a high amylose barley cultivar has a low glycemic index and lower plasma insulin response than one made from a standard barley. $\mathrm{J}$ of Cereal Sci. 2008;48:546-30.

Kooner JS, Saleheen D, Sim X, Sehmi J, Zhang W, Frossard P, Been LF, Chia K-S, Dimas AS, Hassanali N, Jafar T, Jeremy BM, Jowett Xinzhing Li, Radha V, Rees SD, Takeuchi F, Young R, Aung T, Basit A, Chidambaram M, Das D, Grunberg E, Hedman AK, Hydrie ZI, Islam M, Khor C-C, Kowlessur S, Kristensen MM, Liju S, Lim W-Y, Matthews DR, Liu J, Morris AP, Nica AC, Pinidiyapathirage JM, Prokopenko I, Rasheed A, Samuel M, Nabi Shah A, Shera S, Small KS, Suo C, Wickremasinghe AR, Wong TY, Yang M, Zhang F, Abecasis GR, Barnett AH, Caulfield M, Deloukas P, Frayling TM, Froguel P, Kato N, Prasad Katulanda M, Kelly A, Liang J, Mohan V, Sanghera DK, Scott J, Seielstad M, Zimmet PZ, Elliott P, Teo YY, McCarthy MI, John Danesh E, Tai S, Chambers JC. Genome-wide association study in individuals of South Asian ancestry identifies six new type 2 diabetes susceptibility loci. Nat Genet. 2011;43:984-9.

Kumar S, Mohanraj R, Sudha V, Wedick NM, Malik V, Hu FB, Spiegelman D, Mohan V. Perceptions about varieties of brown rice: a qualitative study from Southern India. Am Dietary Assoc. 2011;111:1517-22.

Larsen HN, Christensen C, Rasmussen OW, Tetens IH, Choudhury $\mathrm{NH}$, Thilsted SH, Hermansen K. Influence of parboiling and physico-chemical characteristics of rice on the glycaemic index in non-insulin-dependent diabetic subject. Eur J Clin Nutr. 1996;50:22-7.

Lin MHA, Wu MC, Lu S, Lin J. Glycemic index, glycemic load and insulinemic index of Chinese starchy foods. World J Gastroenterol. 2010;16:4973-9.

Livesey G, Taylor R, Hulshof T, Howlett J. Glycemic response and health a systematic review and meta-analysis: relations between dietary glycemic properties and health outcomes. Am J Clin Nutr. 2008;87:258S-68.

Marsh K, Brand-Miller JC. State of the art reviews: glycemic index, obesity, and chronic disease. Am J of Lifestyle Med. 2008;2:14250.

Matsuo T, Mizushima Y, Komuro M, Sugeta A, Suzuki M. Estimation of glycemic and insulinemic responses to short-grain rice (japonica) and a short-gran rice-mixed meal in healthy young subjects. Asia Pac J Clin Nutr. 1999;8:190-4.

Misra A, Singhal N, Khurana L. Obesity, the metabolic syndrome, and type 2 diabetes in developing countries: role of dietary fats and oils. J Am Coll Nutr. 2010;29:289S-301.

Mitchell HL. The glycemic index concept in action. Am J Clin Nutr. $2008 ; 87: 244$ S- 6 .
Muller W, Bird AR. Glycemic index values and categories are influenced by variability and outlier rejection methodology. Br J Nutr. (submitted)

Murakami K, Sasaki S, Takahashi Y, Okubo H, Hosoi Y, Horiguchi H, Oguma E, Kayama F. Dietary glycemic index and load in relation to metabolomic risk factors in Japanese female farmers with traditional dietary habits. Am J Clin Nutr. 2006;83:1161-9.

Opperman AM, Venter CS, Oosthuizen W, Thompson RL, Vorster HH. Meta-analysis of the health effects of using the glycaemic index in meal-planning. Br J Nutr. 2004;92:367-81.

Panlasigui LN, Thompson LU. Blood glucose lowering effects of brown rice in normal and diabetic subjects. Int $\mathbf{J}$ of Food Sci and Nut. 2006;57:151-8.

Panlasigui LN, Thompson LU, Juliano BO, Perez CM, Yiu SH, Greenberg GR. Rice varieties with similar amylose content differ in starch digestability and glycemic response in humans. Am J Clin Nutr. 1991;54:871-7.

Pi-Sunyer FX. Glycemic index and disease. Am J Clin Nutr. 2002;76:290S-8.

Psaltopoulou T, Ilias I, Alevizaki M. The role of diet and lifestyle in primary, secondary, and tertiary diabetes prevention: a review of meta-analyses. Rev of Diabetic Stud. 2010;7:26-35.

Shaw JE, Sicree R, Zimmet P. Global estimates of the prevalence of diabetes for 2010 and 2030. Diabetes Res Clin Pract. 2010;87:4-14.

Sheu WHH, Rosman M, Chung N, Lim YT, Deerochanawong C, Soewondo P, Lee MK, Yoon KH, Schnell O. Addressing the burden of type 2 diabetes and cardiovascular disease through the management of postprandial hyperglycaemia: an Asian-Pacific perspective and expert recommendations. Diabetes Res Clin Pract. 2011;92:312-21.

Sluijs I, Beulens JWJ, van der Daphne LA, Spijkerman AMW, Grobbee DE, van der Schouw YT. Dietary intake of total, animal, and vegetable protein and risk of type 2 diabetes in the European Prospective Investigation into Cancer and Nutrition (EPIC)-NL Study. Diabetes Care. 2010;33:43-8.

Sun Q, Spiegelman D, van Dam RM, Holmes MD, Malik VS, Willett WC, Hu FB. White rice, brown rice, and risk of type 2 diabetes in US men and women. Arch Intern Med. 2010;170:961-9.

Sweeney MT, McCouch SR. The complex history of the domestication of rice. Ann Bot. 2007;100:951-7.

Tran NAV, Daygon DA, Resurreccion R, Cuevas P, Corpuz H, Fitzgerald MA. A single nucleotide polymorphism on the Waxy gene explains gel consistency. Theor Appl Genet. 2011;123:51925.

Venn BJ, Green TJ. Glycemic index and glycemic load: measurement issues and their effect on diet-disease relationships. Eur J Clin Nutr. 2007;61 Suppl 1:S122-31.

Villegas R, Liu S, Gao YT, Yang G, Li H, Zheng W, Shu XO. Prospective study of dietary carbohydrates, glycemic index, glycemic load, and incidence of type 2 diabetes mellitus in middleaged Chinese women. Arch Intern Med. 2007;26:2310-6.

Walgate, R. Diabetes research for developing countries: European Action on Globel Life Sciences (EAGLES). Nature Biotech. 2008;25:111-16.

Waters DLE, Henry RJ, Reinke RF, Fitzgerald MA. Gelatinization temperature of rice explained by polymorphisms in starch synthase. Plant Biotechnol J. 2006;4:115-22.

Williams, P, J. Brand Miller, and M. Fitzgerald. 2005. Project 4505 GI of rice. Leeton, Australia: cooperative research centre for sustainable rice production: $84-89$.

Wolever TMS, Mehling C. High-carbohydrate-low-glycaemic index dietary advice improves glucose disposition index in subjects with impaired glucose tolerance. Br J Nutr. 2002;87:477-87.

Zhang G, Vasanti MS, Pan A, Kumar S, Holmes M, Spiegelman D, Lin $\mathrm{X}, \mathrm{Hu} \mathrm{FB}$. Substituting brown rice for white rice to lower diabetes risk: a focus-group study in Chinese adults. J Am Diet Assoc. 2010;110:1216-21. 